\title{
Investigation of iron's neurotoxicity during cerebral maturation in the neonatal rat model of haemolysis
}

\author{
Ebru Akar ${ }^{1}$, Aycan Ünalp ${ }^{2}$, Gulden Diniz ${ }^{3}$, Ragip Ortac ${ }^{3}$, Banu Senturk ${ }^{4}$, Osman Yilmaz ${ }^{5}$, Muge Kiray ${ }^{6}$, \\ Merve Tepetam ${ }^{7}$, Canan Coker ${ }^{8}$, Sukru Cangar ${ }^{1}$ \\ ${ }^{1}$ Department of Pediatrics, Dr. Behçet Uz Child Disease and Pediatric Surgery Training and Research Hospital, Izmir, ${ }^{2}$ Department \\ of Pediatric Neurology, Dr. Behçet Uz Child Disease and Pediatric Surgery Training and Research Hospital, Izmir, ${ }^{3}$ Department \\ of Pathology, Dr. Behçet Uz Child Disease and Pediatric Surgery Training and Research Hospital, Izmir, ${ }^{4}$ Department of Biochemistry, \\ Ataturk Training and Research Hospital, Izmir, ${ }^{5}$ Department of Animal Experimentation, Faculty of Medicine, Dokuz Eylul University, \\ Izmir, ${ }^{6} 9$ Eylul University Faculty of Medicine, Balçova, Izmir, ${ }^{7}$ Department of Thoracic Medicine, Faculty of Medicine, Meram \\ University, Konya, ${ }^{8}$ Department of Biochemistry, Faculty of Medicine, Dokuz Eylul University, Izmir, ${ }^{9}$ Department of Pediatrics, \\ Dr. Behçet Uz Child Disease and Pediatric Surgery Training and Research Hospital, Izmir, Turkey
}

\begin{abstract}
Introduction: Haemolytic disease of newborns due to rhesus and $A B O$ incompatibility is encountered frequently in neonatal clinics and may lead to severe haemolysis. In this study, it is suggested that important amounts of iron released with haemolysis may have a toxic effect on the brain parenchymal tissue, and the severity of the toxic effect can be correlated with the maturation of the brain barrier systems. To demonstrate the accumulation and the neurotoxic effects of free iron ( $\mathrm{Fe}$ ) in the brain an experimental haemolysis model with various maturation phases was performed.

Material and methods: The study was composed of 48 Wistar rats with the following ages: five days old (Group A), 10 days old (Group B), and 19 days old (Group C). Each group was divided into three experimental subgroups and three control groups. Experimental groups were treated with intraperitoneal $75 \mathrm{mg} / \mathrm{kg} /$ day phenyl hydrazine hydrochloride for haemolysis.

Results: We demonstrated that the blood brain barrier (BBB) is permeable in five-day-old newborn rats and is mature in 10- and 19-day-old rats. Iron staining and neuronal damage were detected in group $A$ and group $B$ rats. No damage was detected in the brain tissue of group $C$ animals. The presence of iron staining and neuronal damage in group $B$ with mature $B B B$ may suggest the existence of other incomplete barrier systems different from $B B B$ that lead to iron accumulation in the brain.

Conclusions: Blood brain barrier has a partial role in Fe transport, and the alternative barrier systems may also be involved. It could be supposed that after maturation of all barrier systems, excessive Fe penetration to the brain cannot occur. Our findings showed that the toxic amounts of iron may penetrate into the brain parenchyma of newborns despite the BBB preservation and cause neuronal damage in newborns, but the mature brain is not affected by the same magnitude blood levels.
\end{abstract}

Key words: haemolysis, neurotoxic, free iron, brain barrier systems, newborn. 


\section{Introduction}

In neonates, isoimmune and non-immune haemolytic diseases, including Rh, $\mathrm{ABO}$, and subgroup incompatibility disorders, result in toxic heme metabolites, such as bilirubin and iron (Fe). Bilirubin encephalopathy, known as kernicterus, is one of the severe complications of neonatal hyperbilirubinaemia [12,22] and is caused by deposition of unconjugated bilirubin in specific regions of the brain. Blood-brain barrier (BBB) permeability is primarily responsible for exposing the brain to toxic doses of bilirubin; however, the mechanism by which toxic levels of Fe are passed to the brain is poorly understood.

Recent evidence has revealed a connection between Fe and a number of diseases with previously unclear pathogeneses such as Hallervorden-Spatz disease, Friedreich's ataxia, and Huntington chorea. These neurodegenerative diseases are reported to coincide with Fe metabolism disorders and abnormal Fe accumulation $[5,7,14]$. Severe iron toxicity is thought to result from reactive oxygen radicals and lipid peroxidation [18]. Cerebral tissue has high amounts of lipid molecules, so the brain is the most susceptible organ to peroxidation injury [11,12]. Studies of babies with Rh incompatibility have revealed increased byproducts of ferritin and lipid peroxidation. These results support the hypothesis that a high Fe load generates free oxygen radicals and causes cerebral damage $[1,11,17]$. Fe transportation is strictly regulated by the $\mathrm{BBB}$ and other barriers with unclear mechanisms [3]. For instance, rats with congenital BBB defects were shown to have abnormal perivascular Fe deposition [4]. High or low Fe transport rates in critical phases cause cerebral dysfunction in adulthood. The most important phase is the early postnatal period, during which the standard distribution of normal quantities of Fe is necessary for normal myelinisation [24].

The present study creates a rat model of haemolysis with various maturation phases and investigates Fe accumulation and related neuronal damage in the brain.

\section{Material and methods}

To demonstrate the accumulation and the neurotoxic effects of free iron in the brain, we performed experimental haemolysis model in 5-day-old (Group A), 10-day-old rats (Group B), and 19-day-old rats (Group C). Forty-two male Wistar rats from Dokuz Eylul University Faculty of Medicine Experimental
Animal Laboratory were used in this study, following Institutional Ethical Committee approval. According to Vannucci et al. [28], the development of the brain of 7-day-old rat is histologically similar to that of a 3234-week gestation human premature newborn infant. The brain maturation of 12-13-day-old rats resembles term human neonates. Also, 21-day-old rat brains represent the human prepubertal period, when brain development has been completed. Each group of rats was divided into three experimental subgroups and three control groups of seven rats each.

As indicated in previous studies [13,20], a 75-mg/ $\mathrm{kg}$ /day dose of intraperitoneal (IP) phenyl hydrazine hydrochloride $(\mathrm{PHZCI})$ was injected for two days to create the rat model of haemolysis. Phenyl hydrazine immediately reacts with the carbonyl groups of different important biomolecules. It interacts with haemoglobin $(\mathrm{Hb})$ and cytochrome p450 through an oxidation reaction, leading to the generation of destructive free radicals, which are responsible for subsequent haemolysis [15]. During sacrification, ether was used as a general anaesthetic [20]. Blood samples were studied as the indicator of haemolysis. Iron accumulation and the neuronal damage were evaluated by the pathologists.

Control groups received the same volume of $0.9 \% \mathrm{NaCl}$ IP on the first and the second days of the study. Half of the animals of both groups were used for histological studies and the other half for biochemical indicators. In the trial groups haemolysis was induced by IP administration of $75 \mathrm{mg} / \mathrm{kg} / \mathrm{day}$ $\mathrm{PHZCl}$ for two consecutive days based on previous data [13]. On the third day, under general anaesthesia, blood samples were taken for haematological and biochemical tests. Following ventricular perfusion, rats were sacrificed by decapitation, and brain tissue was evaluated histopathologically.

In order to verify the BBB permeability, intracardiac Evans Blue was administered under general anaesthesia to four mature newborn rats (10 days old) and four adult rats (19 days old) and sacrificed after 20 minutes. Frozen sections of brain tissue were evaluated by the Department of Pathology to observe the effects of $\mathrm{PHZCl}$ on the $\mathrm{BBB}$.

\section{Haematological and biochemical tests}

Haemoglobin and Htc levels were evaluated using a hemocounter device and the spectrophotometric method. For biochemical tests, the Diazo and Jendrasik-Grof methods were used to detect plasma 
direct (d.bill) and total (t.bill) bilirubin, respectively. Hyperbilirubinaemia was indicated by a total bilirubin measurement of more than $3 \mathrm{mg} / \mathrm{dl}$ [8]. Aspartate transaminase (AST) and lactate dehydrogenase (LDH) levels were determined. The following methods were also used: the chemiluminescence method for plasma ferritin measurements, the immunoturbidimetric

Table I. Comparison of the biochemical parameters of the A control group with the A trial group

\begin{tabular}{|lccc|}
\hline $\begin{array}{l}\text { Group A } \\
- \text { biochemical } \\
\text { parameters }\end{array}$ & Control group & Trial group & $p$ \\
\hline $\mathrm{Hb}$ & $12.6 \pm 0.97$ & $5.4 \pm 1.62$ & 0.002 \\
\hline Htc & $37.2 \pm 2.84$ & $13.8 \pm 4.2$ & 0.002 \\
\hline t.bill & $0.54 \pm 0.19$ & $2.28 \pm 0.56$ & 0.002 \\
\hline d.bill & $0.41 \pm 0.21$ & $1.2 \pm 0.51$ & 0.004 \\
\hline AST & $59.14 \pm 28.5$ & $223 \pm 79.5$ & 0.002 \\
\hline LDH & $247 \pm 66.3$ & $1403 \pm 706$ & 0.002 \\
\hline Fe & $125.4 \pm 15.8$ & $332.1 \pm 134.9$ & 0.002 \\
\hline TIBC & $246 \pm 80.9$ & $440.5 \pm 66.8$ & 0.002 \\
\hline Ferritin & $22.6 \pm 3.8$ & $37.2 \pm 9.6$ & 0.04 \\
\hline Transferrin & $139.2 \pm 16.9$ & $182.8 \pm 33.3$ & 0.05 \\
\hline
\end{tabular}

Hb-haemoglobin, Htc - hematocrit, t.bill - total bilirubin, d.bill - direct bilirubin, AST - aspartate transaminase, $L D H$ - lactate dehydrogenase, Fe -iron, $T I B C$ - total iron binding capacity

Table II. Comparison of the biochemical parameters of the $B$ control group with the B trial group

\begin{tabular}{|lccc|}
\hline $\begin{array}{l}\text { Group B - } \\
\text { biochemical } \\
\text { parameters }\end{array}$ & $\begin{array}{l}\text { Control } \\
\text { group }\end{array}$ & Trial group & $p$ \\
\hline $\mathrm{Hb}$ & $10 \pm 0.8$ & $6.11 \pm 0.64$ & 0.002 \\
\hline $\mathrm{Htc}$ & $28.6 \pm 2.1$ & $14.7 \pm 2.29$ & 0.002 \\
\hline t.bill & $0.37 \pm 0.13$ & $1.37 \pm 0.36$ & 0.002 \\
\hline d.bill & $0.3 \pm 0.11$ & $0.7 \pm 0.58$ & 0.008 \\
\hline AST & $54.8 \pm 24$ & $175 \pm 25.9$ & 0.002 \\
\hline LDH & $293 \pm 81$ & $1143 \pm 343$ & 0.002 \\
\hline Fe & $135 \pm 41.3$ & $527.7 \pm 178$ & 0.002 \\
\hline TIBC & $373.7 \pm 36.1$ & $645.7 \pm 111$ & 0.002 \\
\hline Ferritin & $23.17 \pm 5.2$ & $34.1 \pm 8.4$ & 0.004 \\
\hline Transferrin & $156 \pm 16.9$ & $179.7 \pm 15.7$ & 0.18 \\
\hline
\end{tabular}

Hb-haemoglobin, Htc - hematocrit, t.bill - total bilirubin, d.bill - direct bilirubin, AST - aspartate transaminase, $L D H$ - lactate dehydrogenase, $\mathrm{Fe}$-iron, $T I B C$ - total iron binding capacity method for transferrin, and the Ferrozine method for Fe and total iron binding capacity (TIBC) measurements (Beckman Synchron Kit).

During pathologic evaluation, the brains of the animals were fixed in $10 \%$ formalin/0.1 $\mathrm{M}$ phosphate buffer, $\mathrm{pH}$ 7.2, and were embedded in paraffin. After these procedures slices $5 \mu \mathrm{m}$ thick were prepared from the frontoparietal cerebral cortex, cerebellar cortex, hypothalamus, thalamus, and choroid plexus. The two samples composed of the same slice were obtained and the first sample was stained using haematoxylin and eosin to show neuronal damage. Two expert pathologists, blinded to the slides observed, evaluated the stained sections to observe the presence of neuronal damage (angular retraction, cell fragmentation, neuronophagia) as well as acidophilia and reactive gliosis in different sections of the brain. Neuronal damage level was evaluated as no damage $(0)$, mild $(+)$, moderate $(++)$, or severe damage $(+++)$ [20]. The second sample stained with Pearl's Prussian blue was evaluated as the absence (-) or presence (+) of intra- and extracellular iron.

\section{Statistical analysis}

The distribution of data is represented using median, minimum, and maximum values. The Kruskal-Wallis and Mann-Whitney $U$ tests were performed for intergroup comparisons of categorical variables. The $\chi^{2}$ and Fisher exact tests were also performed for dichotomous findings. A $p$-value of less than 0.05 was considered statistically significant.

\section{Results}

As a consequence of the induction of haemolysis $\mathrm{Hb}$, Htc, t.bill, d.bill, AST, and LDH levels were significantly different in the study and control groups, as biochemical parameters. A statistically significant difference was observed for the concentration of $\mathrm{Fe}$, TIBC, and ferritin in the study and control groups $(p<0.05)$, but transferrin concentrations were not significantly different $(p>0.05)$ (Tables I-III).

A statistically significant difference was found in $\mathrm{Hb}$ and Htc levels for control A group as compared to control B and C groups (Mann Whitney $U$ Test) $(p<0.05)$. Bilirubin levels were at physiological levels in the studied groups. Significantly increased AST and LDH levels were observed in the experimental group. Although iron and TIBC were significantly increased in the group of haemolysis, ferritin and transferrin levels did not increase. 
Table III. Comparison of the biochemical parameters of the $\mathrm{C}$ control group with the $\mathrm{C}$ trial group

\begin{tabular}{|lccc|}
\hline $\begin{array}{l}\text { Group C - } \\
\text { biochemical } \\
\text { parameters }\end{array}$ & $\begin{array}{l}\text { Control } \\
\text { group }\end{array}$ & Trial group & $p$ \\
\hline $\mathrm{Hb}$ & $10.8 \pm 0.48$ & $6.7 \pm 1.25$ & 0.002 \\
\hline $\mathrm{HtC}$ & $30.6 \pm 2.62$ & $18 \pm 3.1$ & 0.002 \\
\hline t.bill & $0.3 \pm 0.11$ & $0.8 \pm 0.25$ & 0.002 \\
\hline d.bill & $0.21 \pm 0.06$ & $0.42 \pm 0.17$ & 0.014 \\
\hline AST & $65.7 \pm 30.1$ & $228.1 \pm 59.8$ & 0.002 \\
\hline LDH & $241.8 \pm 49.4$ & $1727 \pm 274$ & 0.002 \\
\hline Fe & $161.1 \pm 72.7$ & $406 \pm 109.7$ & 0.002 \\
\hline TIBC & $390.57 \pm 53.8$ & $650 \pm 108$ & 0.002 \\
\hline Ferritin & $11.6 \pm 2.51$ & $23.8 \pm 7.5$ & 0.002 \\
\hline Transferrin & $153.4 \pm 14.1$ & $172.4 \pm 12$ & 0.21 \\
\hline
\end{tabular}

Hb - haemoglobin, Htc - hematocrit, t.bill - total bilirubin, d.bill - direct bilirubin, AST - aspartate transaminase, $L D H$ - lactate dehydrogenase, $\mathrm{Fe}$-iron, $T I B C$ - total iron binding capacity

Both iron accumulation and neuronal damage were evaluated in the control and study groups. The neuronal tissues demonstrate the same degenerative changes
Table IV. Comparison of the neuronal damage in the brain areas between the study groups

\begin{tabular}{|lccc|}
\hline Area of the brain & $\begin{array}{c}\text { Study } \\
\text { Group A }\end{array}$ & $\begin{array}{c}\text { Study } \\
\text { Group B }\end{array}$ & $\begin{array}{c}\text { Study } \\
\text { Group C }\end{array}$ \\
\hline Amygdala & - & - & - \\
\hline Frontoparietal cortex & +++ & ++ & - \\
\hline Hypothalamus & - & - & - \\
\hline Thalamus & - & - & - \\
\hline Choroid plexus & - & - & - \\
\hline Cerebellum & ++ & + & - \\
\hline
\end{tabular}

such as vacuolisation, pyknosis, and cavitations. Herein, these changes were graded as semi-quantified. There was no neuronal damage in the control groups. Neuronal damage was less in the B study group than in the A study group. No damage was detected in the brain parenchyma of the $C$ study group. There was no damage in the hypothalamus, thalamus, or choroid plexus in any of the trial groups (Table IV, Fig. 1).

No Fe accumulation was observed in the control groups. $\mathrm{PHZCl}$-induced haemolysis seemed to cause Fe accumulation in some cerebral regions of some of the trial groups. In fact, there was very little iron


Fig. 1. A) The control rat's cerebrum $(\mathrm{HE} \times 100)$. B) Mild signs of neurodegeneration with vacuolisation $(\mathrm{HE} \times 100)$. C) Moderate degree of neurodegeneration with vacuolisation and pyknosis ( $\mathrm{HE} \times 100)$. D) Severe signs of neurodegeneration with eosinophilic neurons, pyknosis, vacuolisation, and cavitations $(\mathrm{HE} \times 100)$. 


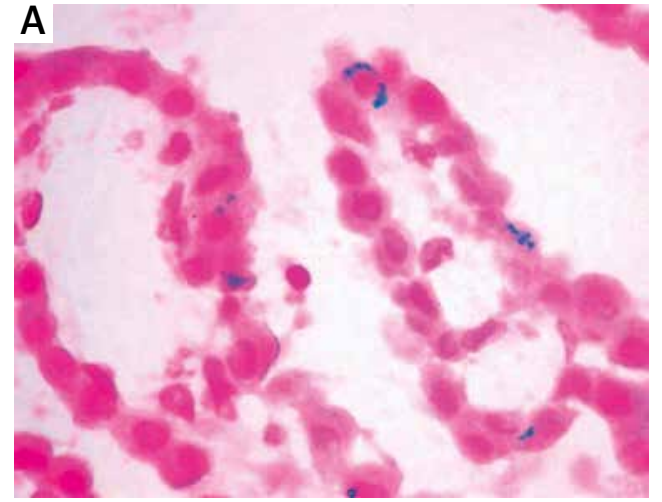

Fig. 2. Intracellular iron deposits in choroid plexus (A) and cerebrum (B) (Pearl's Prussian Blue ×400).

Table V. Comparison of the iron accumulation in the brain areas of the study groups

\begin{tabular}{|lccc|}
\hline Brain areas & $\begin{array}{c}\text { Study } \\
\text { Group A }\end{array}$ & $\begin{array}{c}\text { Study } \\
\text { Group B }\end{array}$ & $\begin{array}{c}\text { Study } \\
\text { Group C }\end{array}$ \\
\hline Amygdala & - & - & - \\
\hline Frontoparietal cortex & + & + & - \\
\hline Hypothalamus & - & - & - \\
\hline Thalamus & - & - & - \\
\hline Choroid plexus & + & + & - \\
\hline Cerebellum & + & + & - \\
\hline
\end{tabular}

accumulation. Therefore, we did not need grading of iron accumulation and we graded iron as being absent or present (Table V, Fig. 2). The presence of iron staining and neuronal damage in B study group with mature BBB supposed the presence of other incomplete barrier systems different from the BBB that lead to iron accumulation in the brain.

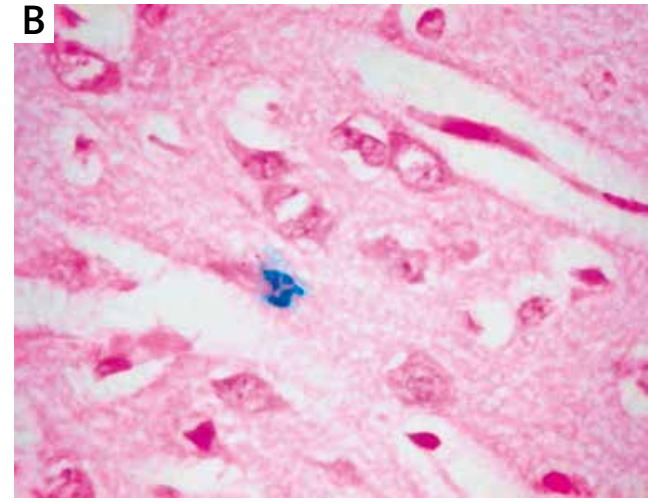

The Evans Blue staining did not pass over the vascular walls of the $B$ and $C$ groups. We demonstrated that BBB was permeable in fibe-day-old newborn rats and was mature in 10- and 19-day-old mature rats (Fig. 3).

\section{Discussion}

Isoimmune haemolytic anaemia related to blood type incompatibility (especially Rh alloimmunisation) is the most common cause of excessive haemolysis and increased heme catabolism. Heme catabolism generates two toxic by-products: bilirubin and heme. Albumin binds free bilirubin, whereas ferritin and transferrin bind Fe, thus minimising the risk of toxicity. However, these "buffer mechanisms" fall short during haemolysis. Increased free bilirubin penetrates the brain during the early neonatal period, when the $\mathrm{BBB}$ is immature, and causes kernicterus. Bilirubin is thought to interfere with oxidative phosphorylation, and protein and glucose metabolism, resulting in neu-
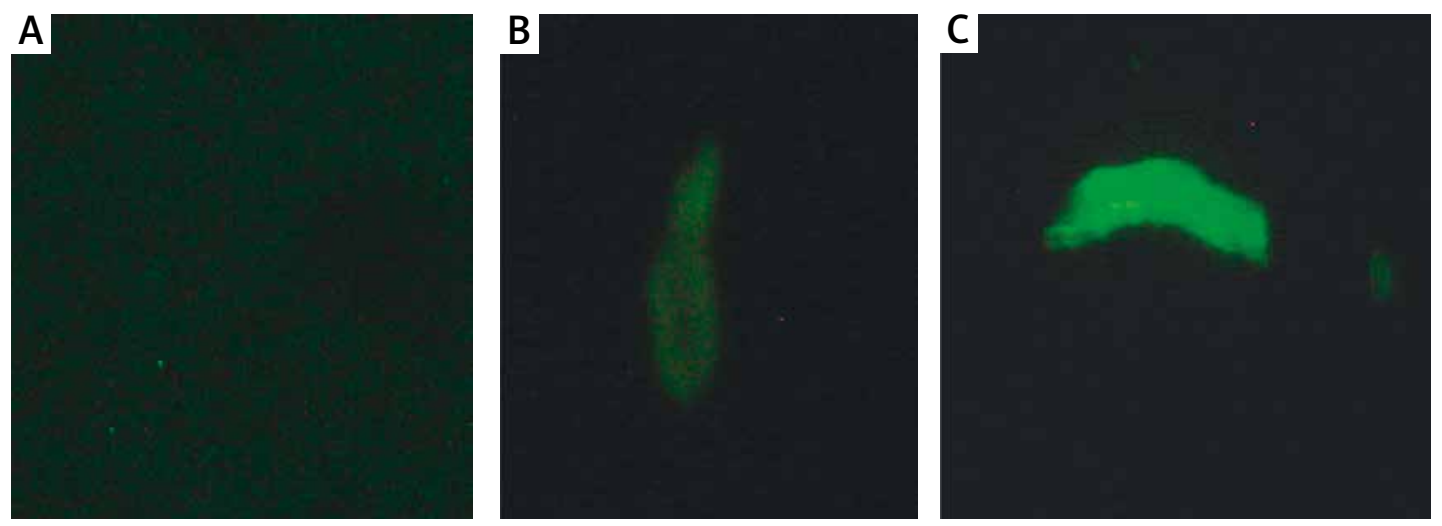

Fig. 3. Evans Blue staining was passed over the vascular wall in Group A (A), B (B), C (C). Evans Blue staining was not passed over the vascular walls of the B and $C$ study groups. 
rotoxic damage [6,19]. Iron causes peroxidation injury in lipid rich tissues and may play a critical role in bilirubin encephalopathy (its pathophysiology is still unclear) and neuronal damage. Iron accumulation and Fe metabolism disorders have been correlated with a number of neurodegenerative diseases; therefore, Fe produced by haemolysis might cause neurologic disorders $[9,29]$. Although hyperbilirubinaemia and its toxic effects during the neonatal period have been well studied, few studies have focused on Fe. In addition, the role of BBB permeability in Fe transportation to the brain is unclear.

In this study, we demonstrated Fe accumulation in special cerebral regions, induced by haemolysis. We also investigated the role of BBB permeability in Fe transportation into the brain. We used semi-quantitative methods to evaluate the degree of neuronal damage in different cerebral regions of rats of different postnatal ages.

To evaluate haemolysis, we evaluated the decrease in $\mathrm{Hb}$ and $\mathrm{Htc}$ levels, the increase in t.bill, d.bill, and $\mathrm{LDH}$, as well as peripheral blood smears. No statistical difference was observed between either the $\mathrm{Hb}$ or $\mathrm{Htc}$ levels of trial groups $A, B$, and C $(p>0.05)$. However, within the control groups, $\mathrm{Hb}$ and $\mathrm{Htc}$ levels were statistically different in Group A compared to Group B and $\mathrm{C}$. We predicted that the normal ranges of $\mathrm{Hb}$ and Htc levels would increase when neonatal maturation was decreased. Therefore, this result has clinical significance as well as statistical significance.

Bilirubin levels were statistically higher in some groups but were still within normal ranges, so no clinical hyperbilirubinaemia occurred. Even with haemolysis, an insufficient increase in bilirubin levels occurred in the Wistar rat model. On the other hand, AST and LDH levels, indicators of cell lysis, were higher in the trial groups than in the control groups $(p<0.05)$. It was concluded that glucuronidation of the bilirubin occurring in the renal and intestinal tissues of the rat is as important as that of the hepatic tissue $[16,20,21]$. Therefore, it might not be possible to establish the higher indirect bilirubin levels necessary to create kernicterus in Wistar rats. Based on this information, we chose to use Wistar rats in order to isolate the effects of Fe from bilirubin. Conversely, use of PHZ caused extremely high t.bill levels in Gunn rats because they have a glucuronyl transferase gene deficiency [25].

Similarly to the study of Mejia et al. [20], the trial groups had significantly increased serum Fe; the increase was clinically consistent. We also investigated ferritin, transferrin, and TIBC in our study, none of which was assessed by Mejia et al. Although TIBC levels were significantly higher, ferritin was higher but still within the normal physiological range in the trial groups. There was no statistically significant increase in transferrin levels. In contrast, Aygun et al. monitored Fe accumulation in Rh alloimmunisation starting from the intrauterine period and found significantly higher levels of ferritin [1]. Similarly, Berger et al. [2] reported that cord blood samples of babies with Rh alloimmunisation had increased ferritin levels, decreased TIBC, normal Fe levels, and increased lipid peroxidation metabolites. The chronic haemolytic process started during the intrauterine period and continued through the postpartum period; moreover, to compensate for increased Fe, ferritin synthesis was increased. In our study, serum Fe levels were increased; however, ferritin levels were in the normal range. Our haemolysis model is limited to acute courses (48 hours), which may explain the lack of increase in ferritin levels. Ferritin synthesis requires additional time and so may fail to compensate for the sudden Fe increase. In addition, other adaptation mechanisms for buffering excessive Fe followed by haemolysis may be ineffective and slow. This also may explain why serum Fe increases, but ferritin and transferrin levels were not increased in our haemolysis model.

The babies with Rh incompatibility, hyperbilirubinaemia and anaemia were treated prenatally and postnatally, but the clinical significance of the increased Fe load is unknown. However, Berger et al. [2] found that increased ferritin coincided with increased lipid peroxidation metabolites. Mejia et al. [20] also reported that Fe and lipid peroxidation metabolites were increased after haemolysis. Excessive Fe loads may predispose cells to free radical damage in neonatal haemolytic diseases. Neonates have limited TIBC and poor antioxidant mechanisms, so they may be susceptible to free radical damage [23]. The neurodegeneration observed in our five- and 10-day old rats, all of which had immature brains, may be explained by this hypothesis.

Frederikson et al. [10] administered an Fe enriched diet to 3-5-, 10-12-, and 19-21-day-old rats. They monitored the rats' behavioural alterations and motor functions and reported that 10-12-day-old rats were more affected than other rats, 19-21-dayold rats were not affected, and 3-5-day old rats 
were mildly affected. These results may indicate a critical period of Fe susceptibility in the brain. The critical period seems to have occurred during an intermediate period, instead of when the brain was least mature. Cerebral Fe uptake in rats peaks between birth and the $15^{\text {th }}$ postnatal day [27]. In this peak period, differentiation in the thresholds of regulatory mechanisms might be responsible for increased cerebral Fe uptake, which may explain why 10-12-day-old rats were most affected by the Fe-enriched diet. Mejia et al. [20] used Evans Blue staining in seven-day-old rats and determined that the BBB was permeable. We showed that 10-day-old rats (representative of $38-40^{\text {th }}$ week foetal brains) and 19-day-old rats (brain maturation was completed) had impermeable BBBs, which may suggest that the BBB does not play a primary role in Fe transportation. In our study, the five-day-old rats with permeable BBBs and the 10-day-old rats with impermeable BBBs had similar Fe accumulation and neuronal damage. No Fe accumulation or neuronal damage occurred in the 19-day-old group. We suggest that the BBB does not have a primary role in Fe transfer; however, immature brains are susceptible to excessive Fe penetration and neurotoxic damage, and mature brains prevent excessive Fe transfer. These results are consistent with those of Frederikson et al. [10].

Mejia et al. evaluated the neurotoxic effects of $\mathrm{Fe}$ in seven-day-old rats with permeable BBBs using semi-quantitative methods. The most damage and Fe accumulation were observed in the frontoparietal cortex. Dense Fe accumulation occurred in the choroid plexus, but the damage was mild [20]. The choroid plexus lacks a BBB, as well as neurons, which may explain these results. Similar to Mejia et al., we observed that five-day-old rats had Fe accumulation in the frontoparietal cortex and choroid plexus. The frontoparietal cortex also had neuronal damage, while the choroid plexus did not. The 10-day-old rats had similar results. Rice et al. [25] reported that in the rat model of hyperbilirubinaemia, some histopathological findings secondary to hyperbilirubinaemia were observed in the cerebellum in 15-day-old Gunn rats. Similarly, we found Fe accumulation and neuronal damage in the cerebellum, but our findings were related to the bilirubin-independent effects of Fe. Iron may predispose rats to the toxic effects of hyperbilirubinaemia.

Castelnau et al. reported that rats with congenital BBB defects had abnormal perivascular Fe accu- mulation, which supports the hypothesis that the BBB is primarily responsible for Fe transfer [4]. In haemochromatosis, intense Fe deposition occurs in the choroid plexus and pituitary gland, where there is no $\mathrm{BBB}$, also suggesting a primary role for the $\mathrm{BBB}$ [26]. However, despite intact BBBs, the 10-day-old rats in our study had Fe accumulation and neuronal damage. Our study proposes that there are other immature barriers, besides the BBB, that may have a role in Fe transfer. Several cerebral regions have higher Fe concentrations on the physiological conditions, including the substantia nigra and the cerebellar nuclei, suggesting that the brain has various regulatory mechanisms and barriers. For instance, cerebrospinal fluid (CSF) helps transport Fe to the brain parenchyma. An hour after Fe injection, Fe is seen in the choroid plexus. Even with low levels of transferrin in circulation, normal Fe uptake levels are observed in the choroid plexus, thus there may also be alternative transport systems between the choroid plexus (that exempts from BBB) and CSF.

The BBB has a major role in bilirubin transport to the brain, and in babies with mature BBBs toxic levels of bilirubin never penetrate into the brain. Our study demonstrates that, unlike with bilirubin, the BBB is not the only determinant for Fe transfer. We observed that rats with permeable BBBs (trial Group A) had Fe accumulation and the most severe neuronal damage. Some rats with impermeable BBBs (trial Group B) also had damage and accumulation and still seemed to experience toxic effects. Trial Group $C$ had neither damage nor accumulation. Per these findings, we propose that the BBB has a partial role in Fe transport, but alternative barrier systems may also be involved, and after the maturation of all barrier systems, excessive Fe penetration to the brain may not occur.

\section{Disclosure}

\section{Authors report no conflict of ineterst.}

\section{References}

1. Aygun C, Tekinalp G, Gurgey A. Increased fetal iron load in rhesus hemolytic disease. Pediatr Hematol Oncol 2004; 21: 329-333.

2. Berger HM, Lindeman JH, van Zoeren-Grobben D, Houdkamp E, Schrijver J, Kanhai HH. Iron overload, free radical damage and rhesus hemolytic disease. Lancet 1990; 335: 933-936.

3. Burdo JR, Simpson IA, Menzies SL, Beard J, Connor JR. Regulation of the profile of iron-management proteins in brain microvasculature. J Cerebral Blood Flow Metab 2004; 24: 67-74. 
4. Castelnau PA, Garrett RS, Palinski W, Witztum JL, Campbell IL, Powell HC. Abnormal iron deposition associated with lipid peroxidation in transgenic mice expressing interleukin- 6 in the brain. J Neuropathol Exp Neurol 1998; 57: 268-282.

5. Connor JR, Menzies SL, St. Martin SM, Mufson EJ. A histochemical study of iron, transferrin, and ferritin in Alzheimer's diseased brains. J Neurosci Res 1992; 31: 75-83.

6. Conolly AM, Volpe JJ. Clinical features of bilirubin encephalopathy. Clin Perinatol 1990; 17: 371-379.

7. Dexter DT, Carayon A, Javoy-Agid F, Agid Y, Wells FR, Daniel SE, Lees AJ, Jenner P, Marsden CD. Alterations in the levels of iron, ferritin and other trace metals in Parkinson's disease and other neurodegenerative diseases affecting the basal ganglia. Brain 1991; 114: 1953-1975.

8. Dominguez F, Gonzales G, Cedars M, Calvo J. Apertura revers ible de la barrera hemato-encefalica inducida por hipercapnia en hiperbilurrubinemia experimental. Ann Espanoles Pediatr 1997; 46: 374-377.

9. Faucheux BA, Nillesse N, Damier P, Spik G, Mouatt-Prigent A, Pierce A, Leveugle B, Kubis N, Hauw JJ, Agid Y, Hirsch EC. Expression of lactoferrin receptors is increased in the mesencephaIon of patients with Parkinson disease. Proc Natl Acad Sci USA 1995; 92: 9603-9607.

10. Fredriksson A, Schröder N, Eriksson P, Izquierdo I, Archer T. Maze learning and motor activity deficits in adult mice induced by iron exposure during a critical postnatal period. Brain Res Dev Brain Res 2000; 119: 65-74.

11. Gutteridge JM, Halliwell B. Free radicals and antioxidants in the year 2000. A historical look to the future. Ann N Y Acad Sci 2000; 899: 136-147.

12. Halliwell B. Iron and damage to biomolecules. In: Iron and Human Disease. Lauffer RB (ed.). CRC Press, Boca Raton 1992; pp. 210230.

13. Hansen TW, Allen JW. Hemolytic anemia does not increase entry into, nor alter rate of clearace of bilirubin from rat brain. Biol Neonate 1996; 69: 268-274.

14. Kienzl E, Puchinger L, Jellinger K, Linert W, Stachelberger H, Jameson RF. The role of transition metals in the pathogenesis of Parkinson's disease. J Neurol Sci 1995; 134 Suppl: 69-78.

15. Latunde-Dada GO, McKie AT, Simpson RJ. Animal models with enhanced erythropoiesis and iron absorption. Biochim Biophys Acta 2006; 1762: 414-423.

16. Li XD, Xia SQ, Lv Y, He P, Han J, Wu MC. Conjugation metabolism of acetaminophen and bilirubin in extrahepatic tissues of rats. Life Sci 2004; 74: 1307-1315.

17. Lindeman JH, van Zoeren-Grobben D, Schrijver J, Speek AJ, Poorthuis BJ, Berger HM. The total free radical trapping ability of cord blood plasma in preterm and term babies. Pediatr Res 1989; 26: 20-24.

18. Malecki EA, Devenyi AG, Beard JL, Connor JR. Existing and emerging mechanisms for transport of iron and manganese to the brain. J Neurosci Res 1999; 56: 113-122.

19. Martinez JC, Garcio HO, Otheguy LE, Drummond GS, Kappas A. Control of severe hyperbilurubinemia in full-term newborns with the inhibitor of bilirubin production Sn-mesoporphyrin. Pediatrics 1999; 103: 1-5.
20. Mejia GB, Sanz CR, Avila MM, Peraza AV, Guzmán DC, Olguín HJ, Ramírez AM, Cruz EG. Experimental hemolysis model to study bilirubin encephalopathy in rat brain. J Neurosci Methods 2008; 15; 168: 35-41.

21. Mottino AD, Pellegrino JM, Guibert EE, Roma MG, Rodriguez Garay EA. Comparison of hepatic, renal and intestinal bilirubin UDP-glucuronyl transferase activities in rat microsomes. Int J Biochem 1988; 20: 1113-1116.

22. Odell GB, Schutta HS. Bilirubin encephalopathy. In: Cerebral Energy Metabolism and Metabolic Encephalopathy. Mc Candles DW (ed.). Plenum, New York 1985; pp. 229-261.

23. Otani H, Engelman RM, Rousou JA, Breyer RH, Das DK. Enhanced susceptibility of immature hearts to free radical mediated reperfusion injury. In: Medical, Biochemical and Chemical Aspects of Free Radicals. Hayaishi O, Niki E, Kondo M, Yoshikawa T (eds.). Elsevier Science Publishers, Amsterdam 1989; pp. 1181-1184

24. Rakic P, Goldman-Rakic PS. The development and modifiability of the cerebral cortex. Overview. Neurosci Res Program Bull 1982; 20: 433-438

25. Rice AC, Shapiro SM. A new animal model of hemolytic hyperbilirubinemia-induced bilirubin encephalopathy (kernicterus). Pediatr Res 2008; 64: 265-269.

26. Russfield A. Diseases of the pituitary. In: Pathology of the nervous system. Minckler J (ed.). Vol 1. McGraw-Hill Book Co, New York 1968; pp. 619-638.

27. Taylor EM, Morgan EH. Developmental changes in transferin and iron uptake by the brain in the rat. Brain Res Dev Brain Res 1990; 55: 35-42.

28. Vannucci RC, Connor JR, Mauger DT, Palmer C, Smith MB, Towfighi J, Vannucci SJ. Rat model of perinatal hypoxic-ischemic brain damage. J Neurosci Res 1999; 55: 158-163.

29. Yokel RA. Blood-brain barrier flux of aluminum, manganese, iron and other metals suspected to contribute to metal-induced neurodegeneration. J Alzheimers Dis 2006; 10: 223-253. 